\title{
Dentistry and COVID -19 - Is there a moral duty of care?
}

SADJ October 2020, Vol. 75 No. 9 p 514 - p517

PD Motloba', H Miniggio², NL Makwakwa

\section{INTRODUCTION}

The world is witnessing the spread of severe acute respiratory syndrome coronavirus 2 (SARS-CoV-2), with countless serious and fatal cases of corona virus disease (COVID-19). The impact of this pandemic has been most devastating among the health professionals due to the nature of their work. The risk of COVID-19 is particularly greater among oral health professionals due to their proximity to the oral cavity and production of aerosols. This scenario then raises the question, is there a moral duty for dental professionals to care for patients when doing so exposes them to significant risks of COVID-19.

Duty of care is considered by most health professionals, synonymous to obligations to care for patients without the possibility of refusal. This duty of a solemn pledge "to treat the ill to the best of one's ability, to preserve a patient's privacy, to teach the secrets of medicine to the next generation..." is often taken in a state euphoria, oblivious to the nature and extent of the sacred promise which places into questions the validity of consent by practitioners to the duty of care..$^{1,2}$

It is well established that the profession of dentistry is amongst the occupations with the highest risk of COVID-19.,4 Most dental professionals consider caring for their patients to be fundamental to their professional duties. Yet most dental professionals do not have a deep understanding of the moral, ethical and legal underpinnings of this obligation. In this article we show that the duty of care, as is generally imposed on practitioners (by society or self) is ethically difficult to defend during times of pandemics, such as COVID-19, using the com-

\section{Author affiliations:}

1. Pagollang D Motloba: BDS (Medunsa), MPH (Epidemiology) (Tulane), Head, Department of Community Dentistry, School of Oral Health Sciences, Sefako Makgatho Health Sciences University. ORCID Number: 0000-0003-1379-7576

2. Hilde Miniggio: BDS (UMF, Cluj-Napoca), MScMed (Bioethics and Health Law) (Wits), PGDip (Health Sciences Education) (Wits), Senior Lecturer, Department of Oral Pathology and Oral Biology, Sefako Makgatho Health Sciences University, South Africa.

3. Nokukhanya L Makwakwa: BDT, BDS (Medunsa) Postgraduate Dip in Clinical Dentistry (UWC), MPH (UL), Registrar, Community Dentistry, School of Oral Health Sciences, Sefako Makghatho Health Science University (SMU), South Africa. ORCID Number: 0000-0001-5669-795X

Corresponding author: Pagollang D Motloba

Department of Community Dentistry, School of Oral Health Sciences, Sefako Makgatho Health Sciences University.

Email: pagollang.motloba@smu.ac.za

Author contributions:

1. Pagollang D Motloba: Primary author - $50 \%$

2. Hilde Miniggio: Second author - $35 \%$

3. Nokukhanya L Makwakwa: Third author - 15\%

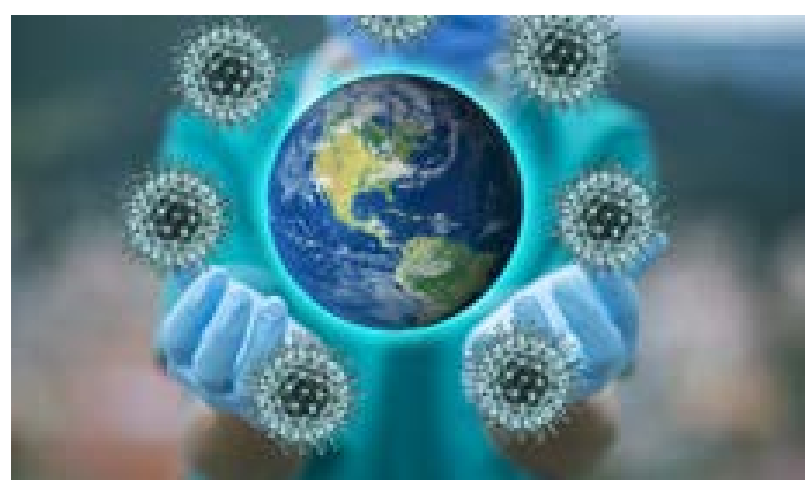

mon contractual and special skills argument. Rather, we argue that the duty to care during pandemics should be considered as a virtue that dental professionals should aspire to as "an ideal of professional character". ${ }^{5}$

While we acknowledge that various duty-based arguments have been proposed, for the purpose of this article, we limit our discussion to the most commonly used arguments of reciprocity and special skills.

This article, addresses the following questions:

i). Is it morally required or expected of dental professionals to treat possible COVID-19 infected patients in the face of considerable risk to themselves and their families?

ii). If so what is the basis of this moral duty or obligation? iii). How far does this duty extend?

iv). How should the health system respond or reciprocate the duty of care by practitioners?

v). Lastly, what becomes of dental professionals who openly refuses to treat symptomatic patients?

\section{Dentistry and COVID-19}

Dental patients may predispose the practitioner to transmissible diseases, amongst others, COVID-19, before, during and after dental treatment. Invariably, dentists perform conical work in closest proximity to the patient's face, mouth and nose, which are the notable the sources of the virus. ${ }^{6}$

Additionally, the dental instruments including, the rotary instruments, 3-in-1 (water and air syringe), and sharp instruments generate generous aerosols and droplets. In dentistry the virus is spread directly through the droplets between persons, and indirectly through contact with contaminated fomites. 
Creation of aerosols makes the viruses airborne and viable over extended periods of time, which is exacerbated by the humidity created in the dental surgery. ${ }^{7}$ As a consequence, dental professionals will inhale suspended airborne virus or contract the virus via the nose, mouth and eyes from the droplets and aerosols that are propelled during coughing and talking. ${ }^{8}$

Despite the risks associated with the severe acute respiratory syndrome coronavirus 2 (SARS-CoV-2) outbreak, dentists have continued to provide essential services to their patients albeit, in a limited fashion. In discharging their duties, most practitioners have relied on symptoms, travel history and telephonic interviews to triage patients, in order to limit transmissions. Unfortunately, these measures are inadequate and do not eliminate the risk of spread of the disease. This means asymptomatic carriers could be presenting for care and spreading the disease in dental practices.

Recent evidence indicates that the asymptomatic carriers may shed the virus for several weeks before becoming symptomatic. The incubation period ranges between 1 and 19 days, during which these patients test negative on RT-PCR. ${ }^{9}$ The false negative results may give a false sense of security to the practioners, and encourage patients to unknowingly spread the infection even more. Unfortunately, most dental practices do not have the capability nor the appetite to provide testing services to patients.

Suffice to say that the provision of dental services places dental practitioners in harm's way every time they chose to treat patients. These acts, selfless or motivated by commercial imperative raise critical moral and ethical questions. A case in point is the reported suicide of a renown E-R doctor in the USA who succumbed to depression due to COVID-19. ${ }^{10}$ This case and similar raises further moral and ethical questions about the expectations of society on practitioners in times of pandemics like COVID-19.

\section{Is the duty of care an obligation or a virtue?}

The ethical foundation of the duty of care derives from the principle of beneficence, which defines the practitioner's obligations towards the wellbeing of their patients, and the establishment of practioner-patient relationship. This special relationship is the stringent form of beneficence by health professionals which is Kantian, or obligation-based in nature. This Kantian obligation is an established culture and universal law among health professionals. Several arguments have been advanced to establish duty of care as a moral obligation. ${ }^{11}$

The most commonly advanced argument is the social contract or reciprocity argument. Protagonists invoke the notion of reciprocity to establish the morality of duty of care. The concept of reciprocity suggests that for benefits and privileges provided and received by health professionals, there is inherent obligation to incur certain risks or commensurate duties. ${ }^{12,13}$ Hence the legitimization of the expectation of the health professionals to lead in the response to COVID-19, despite the associated risks.
Another argument invoked to motivate the duty to care is premised on the fact that health professionals are highly trained and have special skills which enables them to minimize harm to themselves and their patients. ${ }^{14}$ This argument is further supported by consequentialism, a utilitarian moral thought, that seeks to maximize "the greatest happiness for the greatest number". ${ }^{15}$ Hence the expectation by society for the health professional to be at the forefront of the pandemic, saving lives that would otherwise be lost.

The arguments above are a great attempt to establish the moral necessity for a duty of care. However, they fall short in explicating the nature and extent of the duty to care by practioners towards patients. This is because, any duty of care ought to provide a set of minimal standards of conduct which are within the reach of all general professionals. Such prescriptions will enable the codification of duty of care into professional rules. Failure to provide absolute clarity about the extent and nature of duty, makes codification, consent and obligation difficult to interpret. So far, this level of clarity has not been reached and the experience with various infectious diseases, such as, COVID-19, SARS, MERS, H1N1, HIV/AIDS and Ebola highlight the difficulty of imposing absolute duty on clinicians. ${ }^{16,17}$ It is critical for this expectation to be specified apriori, so that consenting professionals are made aware of the risks associated with the benefits accrued. This is unfortunately not the case, and would be unfair to impose the duty of care of clinicians post facto.

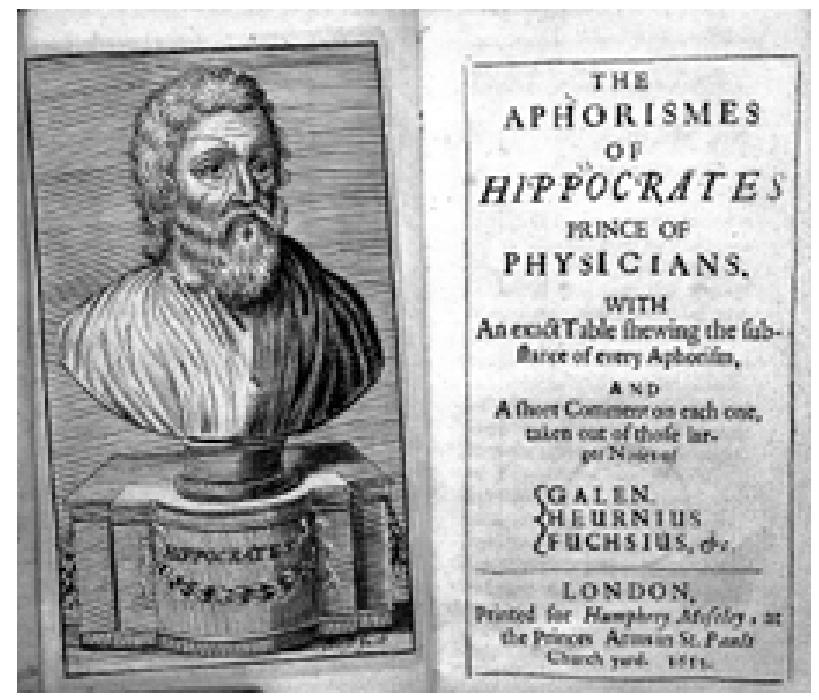

Image source: Wellcome Images, CC BY 4.0

We argue that the COVID-19 related risks are extreme to be obligatory akin to biblical commandments like "thou shall not kill". That the Hippocratic oath and other impositions on health professionals during COVID-19 are not explicit obligations for all professions. The expectation on healthcare professionals to treat patients, often at significant risk to themselves, to their family members and to others, in times of pandemics such as COVID-19 is supererogatory or "going beyond the call of moral duty".

This makes duty of care during such times, a virtuous, saintly and heroic act, thus morally neutral, inconsequential and not required but admirable. In this way, the per- 
spective of a duty of care, changes from a duty-based viewpoint to a character-based trait or virtue, characteristic of a virtuous professional. A virtue is defined as an "acquired habit or disposition to do what is morally right or praiseworthy". ${ }^{18}$ This type of perspective contrasts obligations-based approaches in that the character of the individual is the main concern, combined with emotions and internal motivations. Thus "rights, obligations and duties are not the only sorts of moral considerations that move people to act". ${ }^{19}$

Another form of inspiration for action is to strive for excellence in character or virtues because we are internally motivated to do so. ${ }^{18}$ From a virtue based viewpoint then, "the willingness to care for risky patients is a very good and selfless thing, which exemplifies the highest ideal of the profession". ${ }^{20}$ Furthermore, those healthcare professionals that are prepared to care for patients despite the significant risks "express a virtue of professional character that all physicians should strive for but that not all will achieve". ${ }^{19}$

A virtue-based perspective and virtues are valuable in addressing the duty to care, as it provides significant room for the incorporation of emotions as well as internal motivations. For example, in regards to healthcare professionals that refuse to care for patients in the face of considerable risk to themselves and their family members, Tomlinson writes:

Those who refuse out of an overwhelming fear for themselves, of fear for the safety of their families, should be judged differently from those who refuse because they have no altruism or benevolence, and so have no sense of regret or moral loss when they act solely out of self-interest...such persons can live by the rules, performing as duty demands, but are defective in their professional character. ${ }^{20}$

The incorporation of emotions as part of deliberations of whether or not to provide care to patients is important, as fear for one's safety and the safety of one's family, can be a forceful motivation for action. ${ }^{20}$ More importantly, the capacity of persons to overcome such fears "varies considerably from person to person, and in some persons from occasion to occasion...few of us have perfect mastery over our fear..."20

Thus, considering the duty of care as a virtue which all healthcare professionals should strive for, allows for a more flexible and context dependent approach, in assessing the internal motivations and emotions that lead to individual decisions regarding the duty to care.

We now turn our focus to answer the question: What becomes of dental professionals who openly refuse to treat symptomatic patients? Given the desirability of supererogation in times of pandemics, we advance the view that the profession should not condemn those clinicians who are unable to master the courage to be in the frontline. For those clinicians who prioritize themselves and their families, their actions should not be regarded as uncharacteristic of the professions. Instead we should all strive for the ideals and virtues, such as altruism and empathy. Leaders in health organizations, should thus lead this revolution by example and guided by internal motivations and not sanction dissent. Leaders in health organizations should also be sensitized to the fact that:

Once we acknowledge the aspirational quality of this ideal, we can sympathetically understand that there will be some health professionals - perhaps sometimes many, perhaps even ourselves - who will fall short, not being able to master their fear, for themselves and for their families. And we will appreciate that even good people will have this virtue to varying degrees, in varying circumstances. We will be reluctant, then, to condemn or punish those who are overcome by their fear on particular occasions but whose behavior otherwise suggests their allegiance to the ideal. This stands in contrast to our response to someone's failure to perform a duty, where what is usually called for is moral disapproval, often accompanied by sanctions. ${ }^{20}$

On a final note, anecdote indicates that the role and practice of dentistry has not changed much during the past epidemics, so why would it change now? In fact, majority of patients are likely to postpone routine dental care. For the few who might need dental care, dentists are not obligated to treat COVID-19 positive patients, especially when the nature of care requested is not urgent or necessary. However, the refusing dentist is obligated to refer the patients to colleagues, who are willing and competent.

Treating clinicians must be well protected, this includes by providing the necessary support including IPC (Infection, Prevention and Control) measures and PPEs (Personal Protection Equipment). There is presently a global shortage, which necessitates rational use of these scarce resources. Therefore, clinicians without these armamentaria cannot be expected to discharge their duties. In case of private practitioners, there is an urgent need to review the medical schemes compensation of towards IPC and PPEs.

Presently the provisions by the health care insurance does not encourage strict infection control practices. The costs to transition towards COVID-19 IPC and PPE require massive financial inputs. For most practitioners, it will be financially difficult to establish and sustain the practice.

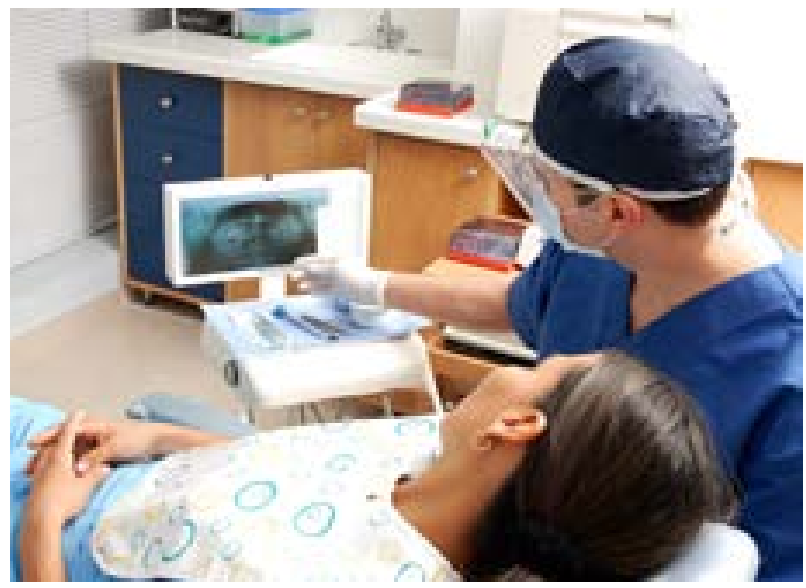




\section{CONCLUSION}

It might be morally defensible but unethical for dental professional to refuse to treat patients. The commonly advanced arguments of reciprocity and special skills, do not offer adequate moral justification for a duty of care in the face of considerable risk to dental professionals.

To impose a moral duty on healthcare workers to treat patients, just because they are health workers is indefensible. A more suitable alternative to invoking the duty of care, is by considering that the provision of care during pandemics such as COVID-19 should be considered as a virtue which "exemplifies the highest ideals of the profession". ${ }^{20}$

Debates about what the duty of care means, how far it extents and the implications thereof, will continue to be the subject of fierce ethical consideration. For oral health, there is a need to test its application in order to guide the professions especially during the COVID-19, and similar future outbreaks. In closing, we propose that the duty of care for patients during pandemics such as COVID-19, should be considered and discussed as a virtue that all healthcare professionals should aspire to, rather than being considered merely as a duty.

\section{References}

1. Holmboe E, Bernabeo E. The "special obligation" of the modern Hippocratic Oath for the $21^{\text {st }}$ century medicine. Med Edu. 2014; 48(1): 87-942.

2. Davey LM. The oath of Hippocrates: an historical review. Neurosurg. 2001; 49: 554-663.

3. Sulmasy D. What is an oath and why should physician swear one? Theor Med Bioeth. 1999; 20: 329-46.

4. Steihm ER. Adverse effects of human immunoglobulin therapy. Transfus Med Rev. 2013; 27: 171-8.

5. Legnani $P$, et al. Atmospheric contamination during dental procedures. Quint Int. 1994; 25: 435-9.

6. Checchi $\vee$ et al. COVID 19 dentistry related aspects: a literature review. International Dental Journal. 2020. https:// doi.org/10.1111/idj.12601.

7. Ather A, et al. Coronavirus disease 19 (COVID-19): implications for dental care. Journal of Endodontics. 2020; 46(9): 1341-2.

8. Ge Z, et al. Possible aerosol transmission of COVID-19 and special precautions in dentistry. Journal of Zhejiang University - SCIENCE B. 2020; 1-8. doi.org/10.1631/jzus. B2010010.

9. Xiao A, et al. Dynamic profile of RT-PCR findings from 301 COVID-19 patients in Wuhan, China: a descriptive study. Journal of Clinical Virology. 2020; doi.org/10.1016/j.jcv.2020. 104346.

10. Watkin, et al. Top E.R Doctor Who Treated Virus Patients Dies by Suicide. The New York Times. Available at: https://www. nytimes.com/2020/04/27/nyregion/new-york-city-doctor-suicide-coronavirus.html/ (Accessed: 19 June 2020).

11. Sokol DK. Virulent epidemics and the scope of healthcare worker's duty of care. Emerg Infect Dis. 2006; 12(8): 1238-41. doi:10.3201/eid1208.060360.

12. Ruderman $\mathrm{C}$, et al. On epidemics and the duty to care: whose duty? who care? BMC Ethics 2006; 7(1): 1-6.

13. Deanery $S$, et al. Healthcare worker's perception of duty to work during influenza pandemic. J Med Ethics. 2010; 36(1): 12-18.

14. Jeffrey DI. Relational ethical approach to the COVID-19 pandemic. J Med Ethics. 2020; 0: 1-4.

15. Hruschka, J. The greatest happiness principle and other early German anticipations of utilitarian theory. Utilitas. 1991; 3(2): 165-77.
16. Singer PA, et al. Ethics and SARS: Lessons from Toronto. BMJ. 2003; 327: 1342-4.

17. Dwyer J, Tsai DF. Developing the duty to treat: HIV, SARS and the next epidemic. J Med Ethics. 2008; 34(1): 7-10.

18. Beauchamp T, Childress J. Principles of biomedical ethics, $2^{\text {nd }}$ ed. New York: Oxford University Press, 1983.

19. Aristotle. Nichomachean ethics. In: McKeon R, ed. The basic works of Aristotle. New York: Random House, 1941.

20. Tomlinson T. Caring for risky patient's duty or virtue? J Med Ethics. 2008; 34(6): 458-62. 